A s i a $\mathrm{n}$ J o u r n a l of

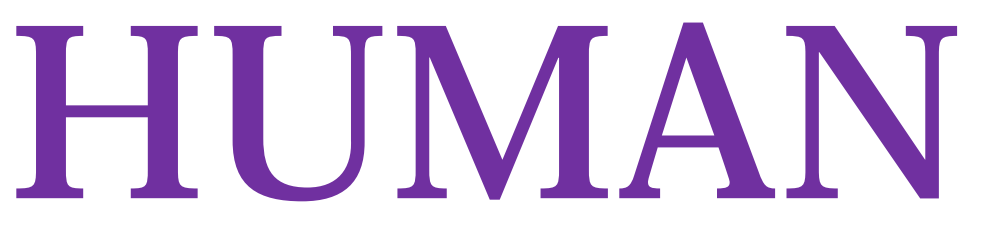

PRINTED 2020.0430 ISSN2188-059X

Published by ASIAN SOCIETY OF HUMAN SERVICES
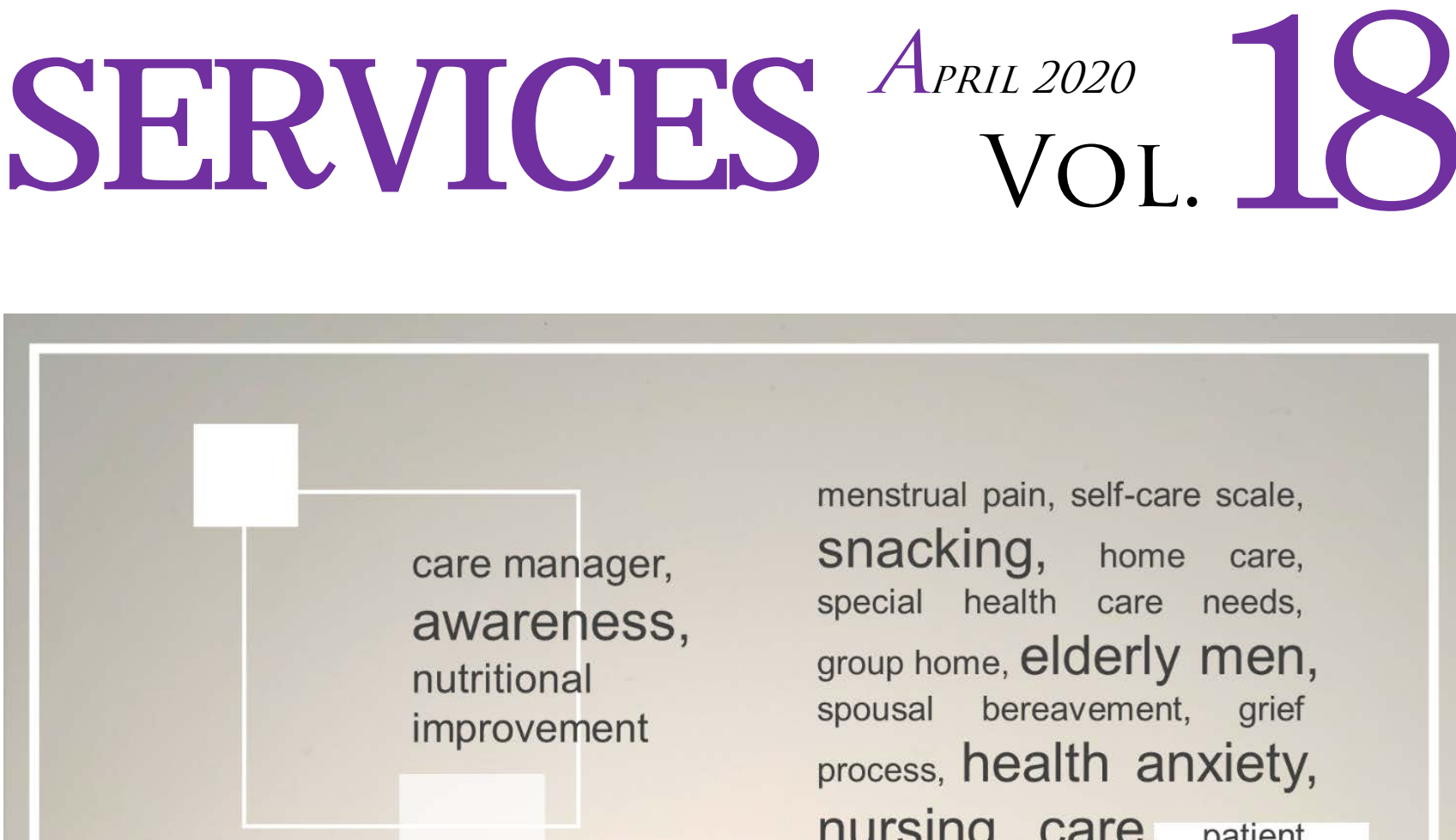

care manager, awareness, nutritional improvement

scale development, teacher training, home health nursing, instructors, down syndrome, verb, reflecting process, graduate students menstrual pain, self-care scale, snacking, home care, special health care needs, group home, elderly men, spousal bereavement, grief process, health anxiety, nursing care, patient acceptance system

Inclusive

education,

ICT utilization

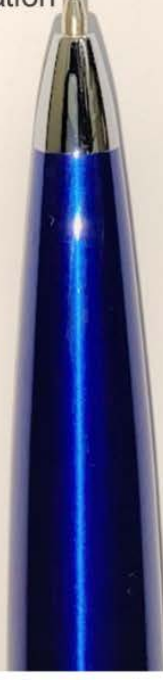




\title{
A Fundamental Study on Health Anxiety in the Daily Life of Visually Impaired People Living in the Community and the Actual Situation of Patient Acceptance Systems at Medical Institutions
}

\author{
Keiko OMOTO 1) \\ 1) Kanto Gakuin University College of Nursing, Japan
}

\begin{abstract}
In Japan, the number of visually impaired persons who develop at the middle of life is increasing because of super-ageing society. They tend to be have psychological stress, and thus decrease their health-related Quality of Life (HRQOL). In this situation, although the role of nurses is extremely important, system of nursing care against adventitious visually impaired patients is not established sufficiently. In this study, we aim to disclose the actual situation of health anxiety of the adventitious visually impaired persons in daily life and the current status and issues of acceptance systems at medical institutions. A semi-structured interview with five patients living in a community revealed that there were many characteristic psychological stresses caused by the health anxiety mainly based on psychological aspect. In addition, it was also found that the lack of patient acceptance system of medical institutions, including the lack of care of medical staff caused mental stress of patients. This study reveals a wide variety of health anxiety
\end{abstract}

Received

March 29, 2020

Revised

April 9, 2020

Accepted

April 13, 2020

Published

April 30, 2020 omoto@kanto-gakuin.ac.jp (Keiko OMOTO; Japan) Asian J Human Services, 2020, 18:48-62. C 2020 Asian Society of Human Services

\section{$<$ Key-words $^{-}>$}

visually impaired, health anxiety, health-related quality of life, nursing care, patient acceptance system 


\section{Introduction}

According to the survey of the Ministry of Health, Labor and Welfare (Japan) in 2016, approximately 312,000 people have a physical disability certificate due to visual impairment in Japan, and approximately 119,000 people in the grade1 (completely blindness) [1]. Visual impairment refers to loss of vision due to blindness and or low vision state of a person, the causes of visual impairment are many and varied; some of them are present at birth and others acquired later in life. The number of people with congenital visual impairment is decreasing, while the number of adventitious visually impaired person who is developed at the middle of age due to age-related eye disease is increasing because of super-aging society compared to the survey twenty years ago. Japanese survey estimated that the patients aged $>20$ and $>60$ accounts for $97.4 \%$ and $72.3 \%$, respectively [2], and more than half of the people with visual impairment were aged 70 years or older. Glaucoma is the leading cause of acquired visual impairment, followed by retinitis pigmentosa, diabetic retinopathy, and age-related macular degeneration [2-3]. These major causes comprised three-quarters of all visual impairment [2]. In addition, those who have the physical disability certificate are considered to be part of the entire visually impaired person, suggesting that it will continue to increase. Therefore, it is estimated that the number of actual visually impaired patients will reach two million by 2030 [4].

Visual impairment markedly reduces the quality of life (QOL) and greatly affects an individual's capacity to maintain social relationships and take part in education or work. It is said that $80 \%$ of people's information input is from vision, and the loss of visual function greatly affects a person's life [5-6]. QOL is assessed in terms of physical status and functional abilities, psychological status and well-being, social interactions, economic and/or vocational status, religious and/or spiritual status [7-9]. One of the fundamental issues in the area of assessment of quality of life is to determine what is important to the individuals' quality of life. The score of Health-related Quality of Life (HRQOL) [10-11] and visual-related Quality of Life (VRQOL) using NEI VFQ-25 (The 25-item National Eye Institute Visual Function Questionnaire) [12] are estimated by the items of not only the difficulty of seeing, but also aspects such as mental health and social function. Because, conventional clinical measures such as visual acuity and visual field assessments do not fully capture the influence of visual disability on daily visual functioning and on abilities to perform activities of daily living that are valued by patients. In particular, HRQOL is thought to be closely related to extending healthy life expectancy [8], and is considered to be an important indicator of the health promotion of the elderly people [13]. Subjective evaluation of HRQOL and health status is recognized as an important tool in the assessment and treatment of visually impaired patients [11]. Visual impairment has a substantial impact on the quality of life, compared with other chronic diseases [11]. Impaired vision significantly reduces activities associated with participation in society and religion, mobility, recreational and daily living etc. 
Vision loss in later life contributes to limitations on physical activity, reduces independent mobility, causes vision impairment and falls, imbalance, entails risks of hip fracture, mortality and underlines the need for community and/or family support. People who develop visual impairment at the middle of life affect change in the quality of physical, psychological, mental, social and economic aspects [14], and the quantitative study by the World Health Organization (WHO) revealed that the score of all aspects are negatively affected their QOL [15]. In particular, adventitious visual impairment causes mental problem accompanied by a deterioration in mental health due to social isolation and anxiety, thus increasing the risk of developing depression [16]. This psychological effect was also found to be significantly stronger in people with blindness than with low vision, and in acquired low-vision people than congenital [16-17]. In this way, there is a difference in the inconvenience in daily life between those with adventitious visually impaired individuals and those who have developed at an earlier stage of life who have been trained and instructed in special education, etc. in childhood [18]. It is important for communities to reduce their specific health anxiety and improve their HRQOL due to visual impairment and visits to medical facilities (including hospitals, clinics, and prescription pharmacies).

When considering improvement of QOL, the ultimate goal of rehabilitation for the visually impaired needs to satisfy "a condition that is physically, psychologically, socially, and physically satisfied." However, in reality, psychological and mental problems tend to be neglected, and their effects are not sufficient [19]. Therefore, there is an urgent need to develop an intervention method and to establish a medical institution with an intervention-type support function that sufficiently promotes psychological adaptation.

In recent years, nurse-led interventions for disease management programs have become increasingly important, including symptom management, relieving and supporting psychological and social stress, lifestyle changes, health education, personalization support, and follow-up support. It was recognized as contributing to comprehensive care [20]. In addition, a survey of the elderly person showed that Nurse-led intervention was effective in improving depression/anxiety symptoms and HRQOL [21]. In this way, it was shown that the nurse-led strategy improved the quality of life of various diseases (cancer, diabetes, etc.) [22]. The importance of nurses who are engaged in both medical care and nursing care for the visually impaired people who are expected to have the role of performing care related to patient QOL is increasing. Therefore, it is very important to accumulate knowledge of nursing care for the visually impaired, but there is still no previous study that provides insights aimed at improving their QOL of the visually impaired, and a sufficient medical system has not been established yet. 


\section{Objective}

The purpose of this study is to focus on the persons who developed visual impairment at the middle of life living in a community, and to evaluate the actual situation of health anxiety in daily life and the acceptance systems at local medical institutions through semi-structured interviews. In addition, we also aim to disclose the current and the actual situation of problems, and to suggest nursing care system to improve their HRQOL in line with the medical system in Japan.

\section{Subjects and Methods}

\section{Patients}

In this study, as a typical example of the visually impaired, we surveyed those who had developed visual impairment at the middle of life (adventitious visually impaired parson). Table 1 summarized the typical information of the respondents. Two persons living alone (living alone) and three persons living with family members as caregivers (living together) were enrolled in this study. All patients were suffered from visual impaired by acquired. Only one patient had complication.

$<$ Table $1>$ Patients characteristics

\begin{tabular}{ccccccccc}
\hline Patient & Gender & Age & Vision & $\begin{array}{c}\text { Cause } \\
\text { disease }\end{array}$ & $\begin{array}{c}\text { Resident } \\
\text { Style }\end{array}$ & $\begin{array}{c}\text { Compli- } \\
\text { cations }\end{array}$ & Onset time & $\begin{array}{c}\text { Outing } \\
\text { frequency }\end{array}$ \\
\hline A & Male & 52 & $\begin{array}{c}\text { Binocular } \\
\text { blindness }\end{array}$ & Glaucoma & $\begin{array}{c}\text { Living } \\
\text { alone }\end{array}$ & No & Adult & Every day \\
\hline B & Male & 59 & $\begin{array}{c}\text { Binocular } \\
\text { blindness }\end{array}$ & Glaucoma & $\begin{array}{c}\text { Living } \\
\text { together }\end{array}$ & No & Adult & $\begin{array}{c}\text { Almost } \\
\text { Everyday }\end{array}$ \\
\hline C & Female & 67 & $\begin{array}{c}\text { Binocular } \\
\text { amblyopia }\end{array}$ & $\begin{array}{c}\text { Retinal } \\
\text { detachment }\end{array}$ & $\begin{array}{c}\text { Living } \\
\text { alone }\end{array}$ & Yes & Adult & $\begin{array}{c}\text { Every other } \\
\text { day }\end{array}$ \\
\hline D & Female & 62 & $\begin{array}{c}\text { Binocular } \\
\text { blindness }\end{array}$ & $\begin{array}{c}\text { Retinitis } \\
\text { pigmentosa }\end{array}$ & $\begin{array}{c}\text { Living } \\
\text { together }\end{array}$ & No & Adult & $\begin{array}{c}\text { Two times } \\
\text { per week }\end{array}$ \\
\hline E & Female & 70 & $\begin{array}{c}\text { Binocular } \\
\text { blindness }\end{array}$ & $\begin{array}{c}\text { Measles } \\
\text { sequelae }\end{array}$ & $\begin{array}{c}\text { Living } \\
\text { together }\end{array}$ & No & Childhood & $\begin{array}{c}\text { Three times } \\
\text { per week }\end{array}$ \\
\hline
\end{tabular}

\section{Interview overview}

We conducted a semi-structured interview survey focusing on health anxiety in daily life and the acceptance system in medical institutions. The interviews were conducted with meeting and telephone with the prior consent of the applicant, and was intended to be used as academic papers for publication. All respondents fully understood the purpose of the study and were extremely cooperative throughout. 


\section{Analysis method}

We qualitatively summarized the words and characteristic sentences from the verbatim list. The obtained answers were counted by category. For the quantitative statistical analysis, the number of answers for each category obtained in the interviews was calculated as ground total by using Microsoft Excel 2013 statistical software.

\section{Ethical considerations}

This study was conducted with the approval of the Kanto Gakuin University Ethics Review Committee (application number: H2019-1-6). Prior to the interview with the surveyees, all participants were explained regarding to the study purpose, study method, expected results, the benefits and disadvantages of the surveyees, any invasive intervention at the time of the survey, voluntary participation, data protection, methods of publication of study results and privacy protection.

\section{Results}

\section{Health anxiety in daily life}

Table 2 summarizes the answers of health anxiety in daily life obtained from the patients. All five patients responded cooperatively.

As shown in table 2 and figure 1, the results of this survey indicate that there are many psychological concerns. In addition, concerns of independence and sanitation were also high, and this anxiety subsequently cause of mental problems. Thus, it obviously shows that psychological anxiety cause by invisible.

In terms of hygiene, anxiety about risks such as digestive tract infections due to eating habits and contact when going out were characteristically indicated. When using toilets in public place or medical institutions, they had to walk while touching doorknobs, handrails, and walls. However, this act may high risk factor of infection because that may be contaminated with viruses and fungi.

In terms of psychological aspect, the influence on independence and self-esteem were strongly pointed out. Even helpers and families who completely understand each other's thoughts affected their shame and self-esteem by checking and collecting their urine and stool. In addition, we can recognize that they have hesitation to ask support for helper regardless of living alone and together. All subjects in this study are acquired visual impairment, and lived independently before onset. Although there may be different emotional changes and processes on acceptance for the onset of visual impairment, these patients tend to be sense of loss because they feel like they can't anything more than before. In the case of person living with others, they answered that there were few problems in their daily lives, but on the other hand, they also found that the burden on the supporting family was big. On the other hand, those who live alone have clearly greater distress in their daily lives, and their loneliness has greatly affected psychological problem because they cannot talk to others about their anxieties. 
$<$ Table 2> Comments on patient anxiety

\begin{tabular}{|c|c|}
\hline Aspects & Comments \\
\hline Independence & $\begin{array}{l}\text { - It was very difficult to live without any helps from a helper for many } \\
\text { things such as moving, reading, writing, cooking, shopping, cleaning and } \\
\text { washing. (Living alone) } \\
\text { - Because the variations of cooking were limited, I tended to eat similar } \\
\text { meals. (Living alone) } \\
\text { - When tendonitis of the elbow joint was developed, it was difficult to } \\
\text { apply a cold compress to the affected area with one hand. (Living alone) } \\
\text { - I didn't know the box or the amount to take even if I wanted to take cold } \\
\text { medicine such as a prescription medicine. (Living alone) } \\
\text { - I think that the degree of distress was low because the spouse performed } \\
\text { all of the daily chores. (Living together) } \\
\text { - It was difficult to check urine and stool color as a health self-check and } \\
\text { to collect urine and stool at home as instructed by a doctor. (Living alone } \\
\text { and together) }\end{array}$ \\
\hline Economics & $\begin{array}{l}\text { - I was unable to work and had to move to a municipal house to live with } \\
\text { low income. (Living alone) }\end{array}$ \\
\hline Sanitation & $\begin{array}{l}\text { - It was difficult to notice the decay of foodstuffs, and even if mold was } \\
\text { breeding on bread and the like, it could not be noticed and sometimes } \\
\text { eaten. (Living alone) } \\
\text { - Infection of tinea versicolor was left for a long time until the helper } \\
\text { noticed. (Living alone) } \\
\text { - I did not notice my own hyperemia in the eye. (Living alone) } \\
\text { - During menopause, hospital visits were delayed due to unaware of } \\
\text { irregular bleeding. (Living together) } \\
\text { - Even when I tried to wash my hands, I couldn't wash even the dirt that } \\
\text { healthy people could recognize. (Living alone) } \\
\text { - When going out, there were concerns about hygiene such as fingers and } \\
\text { handrails due to handrails in public toilets and contact with walls. (Living } \\
\text { alone and together) }\end{array}$ \\
\hline $\begin{array}{c}\text { Activities / } \\
\text { Behavior }\end{array}$ & $\begin{array}{l}\text { - I was afraid to go out because of my experience of falling and breaking } \\
\text { my leg. (Living alone) } \\
\text { - I rarely went out, and often watched TV alone at home. (Living alone) } \\
\text { - When my spouse was absent, I often needed to go to a medical } \\
\text { institution alone. (Living together) } \\
\text { - I want to karaoke, but I have no friends, then I can't. (Living alone) }\end{array}$ \\
\hline Psychologic & $\begin{array}{l}\text { - I used to clean it before because I liked it cleanliness, but now I can't see } \\
\text { any dirt, so I stopped cleaning myself. (Living alone) } \\
\text { - I always depend on my spouse, and there is a feeling of loss that I can't } \\
\text { do anything. (Living together) } \\
\text { - I know information about Coronavirus Disease } 2019 \text { (COVID-19), but I } \\
\text { am worried that it is easy to get infected because there were many chances } \\
\text { to touch on railings and walls. (Living alone) } \\
\text { - If I can see, I can do the same as a sighted person, but there is irritation } \\
\text { that I cannot do it alone because I can't see. (Living together) } \\
\text { - I was taking stabilizers because I was afraid that I couldn't see. (Living } \\
\text { alone) } \\
\text { - I can't help feeling lonely because my spouse died. (Living alone) } \\
\text { - I want to go out and chat with people, but I feel lonely because I cannot } \\
\text { go out freely. (Living alone) } \\
\text { - I was ashamed to ask a helper or spouse to collect urine or stool. (Living } \\
\text { alone and together) }\end{array}$ \\
\hline $\begin{array}{c}\text { Medical } \\
\text { institution }\end{array}$ & $\begin{array}{l}\text { - When I visited a clinic with a guide dog, I was declined the consultation } \\
\text { because dog is not permit to enter the clinic. (Living together) } \\
\text { - It was difficult to understand the doctor's explanation after receiving } \\
\text { the image diagnosis. (Living alone) }\end{array}$ \\
\hline
\end{tabular}




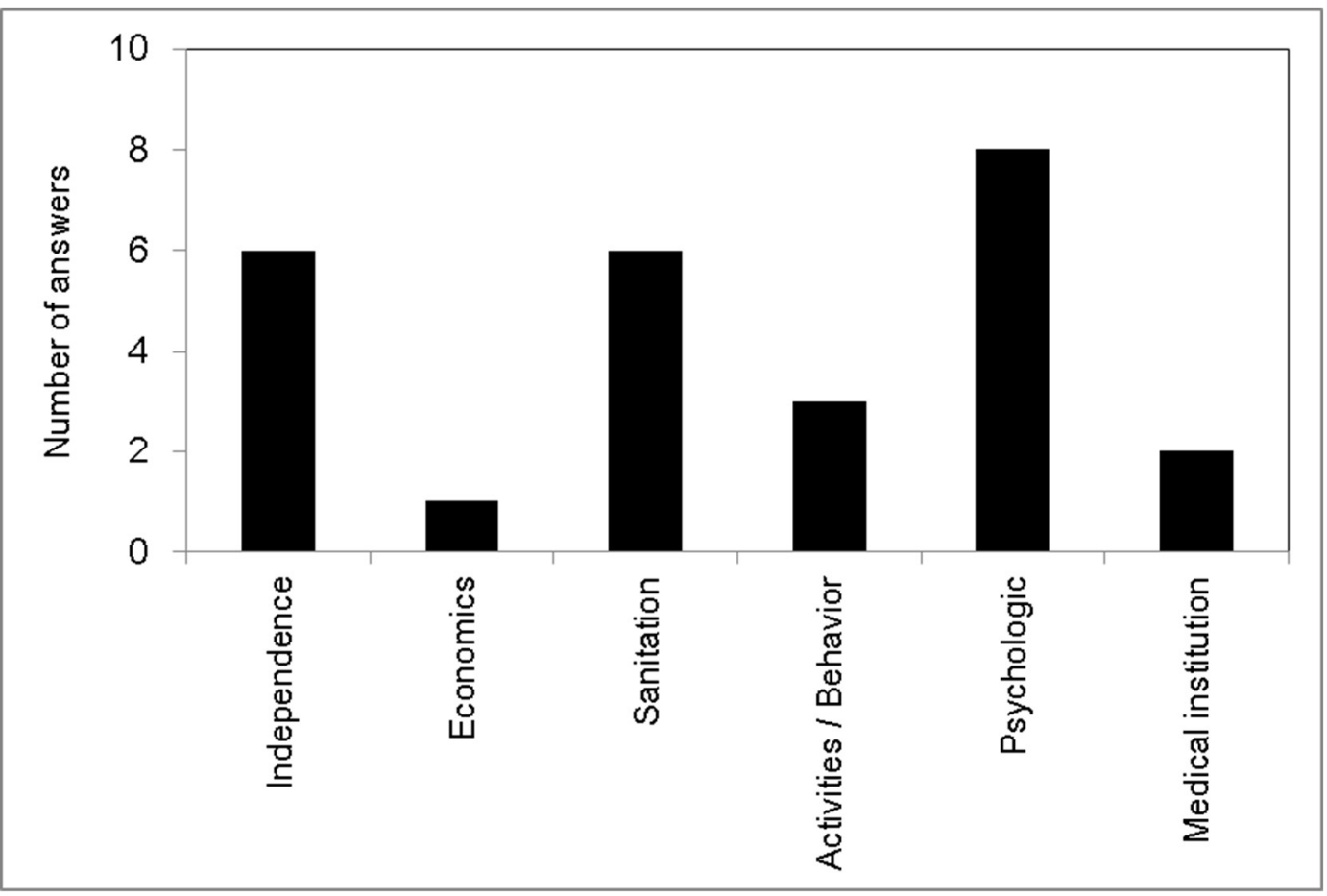

$<$ Figure 1> Answers frequency on each aspects

They had less expectation of having a partner in the rest of their life, and thus they have great mental burden than healthy people or visually impaired person living with helper.

In terms of behavioral impacts, it was found that appropriate assistance led to improve their health. Regarding the pain of tendonitis, it was difficult to take actions alternative way such as cooling and hot compress as self-control for pain relief other than cold compresses. This means that self-care actions could not be taken by incorporating information about health from the viewpoint of health literacy, and this was a very disadvantageous situation for maintaining a healthy state. In addition, there was fear when a COVID-19 disease or influenza virus infection expanded, and they felt that information sharing was essential.

Furthermore, if they want to consult a medical institution due to sudden illness, it is not easy to request a temporary or emergency helper to accompany. Therefore, there was a risk of worsening due to delay visit to hospital. Originally, they had no limb / trunk problems, but tended to have a narrow range of action due to visual impairment, muscular weakness due to lack of exercise, and a decrease in bone mineral density due to reduced opportunities to go out. In this circumstances of life style, they have high risk suffer from lifestyle-related illness and frailty. 


\section{Anxiety about acceptance system at medical institutions}

Significant confusion was observed in the inadequate system of medical institutions, including the lack of care for healthcare workers, which could lead to medical distrust from visually impaired person. Patients often went to the hospital alone by taxi when needed. However, it was disclosed that medical institutions did not have enough staff to provide safe and secure guidance. Most taxi drivers can provided guidance to the hospital entrance, but it was extremely difficult for visually impaired person to move from the entrance to the reception / waiting room, treatment room, and examination room by themselves.

For example, in a dental treatment room, there are many devices in a narrow place, so when entering and leaving the room, it is always dangerous to hit somewhere, touch sharp objects, hit the head with a lighting equipment, etc. In addition, they experienced fear of "what will be done now" and anxiety of "how much time is spent in a place where strange sound" due to the lack of explanation at the time of examination/treatment, especially in CT/MRI examination. Furthermore, the explanation of the image diagnosis results from the doctor was almost the same as the explanation for sighted people, or it was difficult to understand because the explanation was omitted, and the way of explanation for the visually impaired was not devised. At out-of-hospital prescription pharmacies, it was difficult to distinguish multiple prescribed eye drop containers because they have the same shape, and multiple different eye drops must be applied to the left and right eyes.

In situation without sufficient explanation, he had to rely on his family and helpers for medications. Patients claimed that despite the fact that there are multiple prescription drugs for oral medicines, they have similar shape of the sheet, making it difficult to distinguish the medicine. Thus, it became clear that there were many psychological stresses caused by the inadequacy of the medical institutions' acceptance system.

\section{Discussion}

The results of this study have revealed that psychological effects are particularly large in persons with adventitious vision impairment. The mechanisms of QOL decline in visual impairment were explained as being caused by a change in four items including (1) limiting daily activities, (2) socio-economic impacts such as income and financial burden, (3) social impacts such as social integration and perceived support, (4) psychological effects such as self-efficacy [23]. In Japan, the proportion of visually impaired people in the total disability is relatively rare, and it is difficult to link to rehabilitation, employment support, and community life support. In addition, research on assisting people with adventitious disabilities has been focused on people with physical disabilities and has not adequately addressed the needs of people with adventitious visual impairment [24]. 
On the other hand, in the United Kingdom, which is an advanced country for disabilities, there is a key facility (Royal National Institute of Blind People (RNIB), which leads to independent living in the community immediately after blindness of patients. The RNIB provides (1) visual impairment rehabilitation, (2) psychological support, (3) vocational rehabilitation, (4) employment support, (5) inclusive education services, and other support services [23]. For the adventitious visually impaired person, not only improves visual function but also psychosocial integrated rehabilitation approach that provides support through counseling and interventions are needed. However, there are not enough programs yet.

One of the most effective treatments in the psychological field is cognitive behavioral therapy (CBT) [25]. CBT group interventions and counseling have been reported to improve mental health in the visually impaired [26-27]. Recently, it has been shown that CBT with Nurse-led intervention improved depression symptoms [28-29]. It has also been shown clinically that mindfulness training was effective in reducing depression in the visually impaired [30]. Mindfulness contributes to improving the mental well-being of the visually impaired by increasing the sense of intra-person, interpersonal, and transpersonal "connections" and it is thought to be related to the increase in selfawareness of emotional, social, and physical health. In this way, CBT and mindfulness practice are expected to have an effect on the visually impaired persons like surveyed in this study, and could be a focus for establishing nursing care system in the future.

\section{Consideration of the role of nurses for the visually impaired person}

Although the number of elderly people with visual impairment including low vision is expected to increase in the future, specialized facilities that provide information and care to them are limited. It is easy to imagine from the results of present study that there are not a few patients who have living without getting to the appropriate information. It is not possible to deal with the visually impaired with only a limited number of specialized institutions and professions, and it is necessary to seek cooperation with many multidisciplinary occupations that provide medical care in the community. Nurses are at the forefront of this, and it is thought that it is necessary for nurses to establish a cooperative system with clinicians, occupational therapists, care managers and so on. Therefore, we suggest the following nursing care recommendations for the visually impaired person.

\section{1) Respect individuals}

It is important to communicate effectively, and most importantly, to recognize visually impaired patients as people with the same needs and emotions as those with normal vision. It is also essential to respect individual needs and to recognize and understand how best to address them. In such a case, it is necessary to respond carefully to the patient without interrupting the patient's talk. 


\section{2) Understand the psychological stage}

It has been reported that visually impaired persons have at least five stages of disability acceptance [14]. Therefore, it is necessary to recognize the age of onset of low vision, understand needs, and treat care for patients with visual impairment carefully and individually.

\section{3) Recover patient confidence}

The goal of society is to help the visually impaired patients to integrate by supporting everything they do, and restoring self-confidence is one of the most important tasks for them. Family and helper support the visually impaired person, which on the other hand, it sometimes lead to loss of patient's confidence. Similarly, the involvement of nurses should be kept at a moderate level so that personal confidence is not compromised.

\section{4) Understand the situation}

If any subjective symptoms occur, medical staff must fully understand that visually impaired persons must rely on medical institutions, especially because self-control is difficult. It is also important to feel the inconvenience of the patient and to make the environment easy to talk about. In addition, she will act as a spokesman for the patient and try to explain it to a specialist and provide appropriate responses.

\section{5) Sufficient explanation}

It will provide basic and very important information on symptoms, such as how the visual impairment progresses specifically and how long it will take. Therefore, nurses should be aware that they are in the position to most strongly define "how to accept disabilities" for blind people. Nurses also advises on how to self-manage the medicine.

\section{6) Reduce the burden on family members and caregivers}

There is a need to reduce the stress of supporters due to the increasing need for family and community support. In the case of elderly patients, dementia may also occur. In such a case, if it is not possible to sufficiently explain one's own symptoms, information on family members and caregivers is important. Listen to vague information from family and caregivers, such as "something different than usual." In addition, family members and caregivers should confirm their goals of "inferring the patient's view of life and values" and strive to reduce the burden on each other as much as possible. Of course, it is also important to take a neutral position so that family relationships do not worsen.

\section{7) Beware of complications}

It is conceivable that life problems will differ depending on the presence or absence of complications. Elderly people will suffer further decline in HRQOL due to the overlap with visual impairment, in addition to reduced physical fitness, reduced resistance to disease. 
In addition, when a diabetic patient has visual impairment, self-management such as diet, exercise, blood glucose self-measurement, and insulin self-injection is greatly impeded, and the support of an assistant is indispensable. In addition, the risk of aspiration and oral care should be carefully monitored to ensure early detection of the disease.

\section{8) Enlighten nurse education}

Given that the lack of visual information is a psychological and physical barrier to consulting medical institutions, it can be pointed out that there is great room for consideration of feedback to healthcare professionals in education. It is also important to keep daily nursing records for nursing education.

\section{9) Increase awareness of belonging.}

People with visual impairment have strong self-esteem, participation in group sessions is useful for improving individual behavior, and ensuring mutual communication is important. Therefore, it is recommended that you consult for telephone support, online support, and interview support. In addition, we provide information on various services and rehabilitation that can be received as a visually impaired person. Also, let them know that there are people who are nearby.

\section{0) Countermeasures against infectious diseases}

Visually impaired persons were found to be at higher risk for contact and droplet infections. For this reason, it is necessary to provide information on the occurrence of infectious diseases and accurately communicate what to be careful not to give as anxiety. In addition, cleaning and wiping should be performed frequently.

\section{Welfare issues}

Despite the fact that the population ratio of the grade1 of physical disability certificate due to visual impairment is about 1 in 1,000 , it is extremely rare to see visually impaired people who go out with white sticks in towns and public transportation etc.

In Japan, there are not many medical institutions where visually impaired persons are allowed to enter with guide dogs. Psychological problems, inadequate barrier-free services, and inadequate welfare policies are assumed as factors not to go out, but it is thought that the "stay-at-home" due to reduced opportunities for social participation can lead to a deterioration in mental health.

In the future, as the entire Japanese society is focusing on barrier-free preparations for the Tokyo Paralympic Games, reviewing and improving the medical system at medical sites in Japan is an urgent issue. There is also a need to develop a smartphone that utilizes $\mathrm{AI}$ and is easy for visually impaired people to use. Furthermore, it can be said that Japan has a high risk of natural disasters such as earthquakes and eruptions, and it is necessary to make effective use of Braille and voice guides in order to adequately prepare emergency communications and environmental measures. 


\section{Study limitation}

It was very difficult to collect the large number of visually impaired persons who will be the subjects of this study. As mentioned in this article, having a visual impairment at the middle of life can be expected to have various different difficulties depending on the age at onset, gender, social position, etc.

Therefore, it is necessary to examine in more detail the bias of congenital and acquired, gender, and region in future research. In addition, quantitative analysis before and after intervention is needed to measure the improvement of QOL. For example, with regard to HRQOL, the use of The Nottingham Adjustment Scale Japanese version (NAS-J), a scale that measures rational adaptation including the seven psychological variables (anxietydepression, self-esteem, attitude to disability, locus of control, acceptance of disability, selfefficacy and attributional style), is effective [31]. We also consider that low vision qualityof-life questionnaire (LVQOL) [32] and Depression Anxiety Stress Scales (DASS) [33-34] are useful for measuring VRQOL and mental health scales, respectively.

\section{Conclusion}

This study disclosed the existence of various factors of health anxiety in daily life that adventitious visually impaired person living in a community, and some of the inadequacy of the acceptance systems at medical institutions. This study has provided a lot of insights towards to examine in details the nursing care practice needed to improve HRQOL for the visually impaired persons.

\section{Conflict of interest}

There are no companies with conflicts of interest to disclose in connection with this study.

\section{References}

1) Ministry of Health, Labor and Welfare, Social Welfare and War Victims' Relief Bureau, Department of Health and Welfare for Persons with Disabilities (2018) Heisei 28 Nen Seikatsu no Shizurasa ni Kansuru Chosa Zenkoku Zaitaku Shougaiji • Sha Nado Jixtutai Chousa Kextuka.(in Japanese)

2) Morizane Y, Morimoto N, Fujiwara A, Kawasaki R, Yamashita H, Ogura Y et. al. (2019) Incidence and causes of visual impairment in Japan: the first nation-wide complete enumeration survey of newly certified visually impaired individuals. Japanese Journal of Ophthalmology, 63(1), 26-33.

doi: 10.1007/s10384-018-0623-4. 
3) Japan Federation of the Visually Impaired (2019) Wagakuni no Shikaku Shougaisha no Shourai $\sim$ Shouraibijon Kentou Iinkai Houkokusho . (in Japanese)

4) Yamada M, Hiratsuka Y, Roberts CB, Pezzullo ML, Yates K, Takano S, et. al. (2010) Prevalence of visual impairment in the adult Japanese population by cause and severity and future projections. Ophthalmic Epidemiology, 17(1), 5057. doi: 10.3109/09286580903450346.

5) Katoh H (2017) Origin and future of the theory that humans have obtained $80 \%$ of information input from vision. National University Corporation Tsukuba University of Technology Techno Report, 25 (1), 95-100.

6) Suzukamo Y (2017) Mental health of people with low vision and their family. The Japanese Journal of Rehabilitation Medicine, 54, 429-432.

7) Doi Y (2004) Introduction-conceptual issues on Quality of Life (QOL) and Importance of QOL Research, Journal of the National Institute of Public Health, 53(3), 176-180.

8) The WHOQOL Group (1998) The World Health Organization Quality of Life Assessment (WHOQOL): development and general psychometric properties. Social Science \& Medicine, 46(12), 1569-1585. doi: 10.1016/s0277-9536(98)00009-4.

9) Saxena S, Carlson D \& Billington R; WHOQOL Group. World Health Organisation Quality Of Life (2001) The WHO quality of life assessment instrument (WHOQOL-Bref): the importance of its items for cross-cultural research. Quality of Life Research 10(8), 711-721. doi: 10.1023/a:1013867826835.

10) Ware JE Jr \& Sherbourne CD (1992) The MOS 36-item short-form health survey (SF-36). I. Conceptual framework and item selection. Medical Care, 30(6), 473483.

11) Langelaan M, de Boer MR, van Nispen RMA, Wouters B, Moll AC \& van Rens GHMB (2007) Impact of visual impairment on Quality of Life: A comparison with Quality of Life in the general population and with other chronic conditions. Ophthalmic Epidemiology, 14(3), 119-126. doi: 10.1080/09286580601139212.

12) Suzukamo Y, Oshika T, Yuzawa M, Tokuda Y, Tomidokoro A, Oki K et al. (2005) Psychometric properties of the 25-item National Eye Institute Visual Function Questionnaire (NEI VFQ-25), Japanese version. Health Qual Life Outcomes, 3(65), 1-11. doi: 10.1186/1477-7525-3-65.

13) Dev MK, Paudel N, Joshi ND, Shah DN \& Subba S (2014) Psycho-social impact of visual impairment on health-related quality of life among nursing home residents. BMC Health Services Research, 14, 1-7. doi: 10.1186/1472-6963-14-345. 
14) Omoto $K$ \& Hirakawa $M$ (2020) Literature review of various issues and practice care for the visually impaired after becoming an adult; From the viewpoint of nursing education. Journal of Inclusive Education, 8, 46-56. doi: org/10.20744/incleedu.8.0_56.

15) Amedo AO, Adade S, Koomson NY \& Osae EA (2016) Influence of visual impairment on the quality of life: A survey of patients reporting at the low vision centre of the eastern regional hospital of Ghana, Journal of ophthalmic science, 1(3), 1-13. doi: 10.14302/issn.2470-0436.jos-16-940.

16) Choi HG, Lee MJ \& Lee SM (2018) Visual impairment and risk of depression: A longitudinal follow-up study using a national sample cohort. Scientific Reports, 8(1), 1-8. doi: 10.1038/s41598-018-20374-5.

17) Choi SU, Chun YS, Lee JK, Kim JT, Jeong JH \& Moon NJ (2019) Comparison of vision-related quality of life and mental health between congenital and acquired low-vision patients. Eye (Lond), 33(10), 1540-1546. doi: 10.1038/s41433-0190439-6.

18) Sasahara A, Kobuke Y, Murai M, Ohmitsu M \& Yoshitake T (2016) Survey of medicine use of the acquired visual disabilities. Japanese journal of social pharmacy., 35 (2), 69-79.

19) van Nispen RM, Virgili G, Hoeben M, Langelaan M, Klevering J, Keunen JE, et. al. (2020) Low vision rehabilitation for better quality of life in visually impaired adults. Cochrane Database of Systematic Reviews 1-146. doi: 10.1002/14651858.CD006543.pub2.

20) Kivelä K, Elo S, Kyngäs H \& Kääriäinen M (2020) The effects of nurse-led health coaching on health-related quality of life and clinical health outcomes among frequent attenders: A quasi-experimental study. Patient Education and Counseling, In press. doi: 10.1016/j.pec.2020.02.026.

21) Markle-Reid M, McAiney C, Forbes D, Thabane L, Gibson M, Browne G, et al (2014) An interprofessional nurse-led mental health promotion intervention for older home care clients with depressive symptoms. BMC Geriatrics. 14 (62), 1-23. doi: 10.1186/1471-2318-14-62.

22) Cheng X, Wei S, Zhang H, Xue S, Wang W, Zhang K, et. al. (2018) Nurse-led interventions on quality of life for patients with cancer: A meta-analysis. Medicine (Baltimore), 97(34), 1-8. doi: 10.1097/MD.0000000000012037.

23) Brown RL \& Barrett AE (2011) Visual impairment and quality of life among older adults: an examination of explanations for the relationship. The journals of gerontology. Series B, Psychological sciences and social sciences 66(3), 364-373. doi: 10.1093/geronb/gbr015.

24) Kashikura H (2017) Situations of Support for People with Aquired Visual Disabilities in the UK: Focusinf on ECLO's Role Promoted by RNIB. Journal of social welfare, Nihon Fukushi University, 136, 1-14 
25) Utoyo DB (2015) Modifying cognitive-behavioral therapy for a depressed older adult with partial sight. A Case Report, Gerontology and Geriatric Medicine. 1-3. doi: 10.1177/2333721415585432.

26) Sefat ES, Younesi SJ, Dadkhah A \& Rostami M (2017) Effectiveness of cognitive behavioral therapy training in reducing depression in visually impaired male students, Iranian Rehabilitation Journal, 15(2), 165-172.

doi: 10.18869/nrip.irj.15.2.165.

27) Collin D. Mullins (2019) Cognitive behavioral group therapy for blind and visually impaired adults: Acceptance, problemsolving, and cognitive distortions. Philadelphia College of Osteopathic Medicine, 1-110.

28) Tanoue H, Yoshinaga N, Kato S, Naono-Nagatomo K, Ishida $Y$ \& Shiraishi $Y$ (2018) Nurse-led group cognitive behavioral therapy for major depressive disorder among adults in Japan: A preliminary single-group study. International Journal of Nursing Sciences 5(3), 218-222. doi: 10.1016/j.ijnss.2018.06.005.

29) Currid TJ, Nikcević AV \& Spada MM (2011) Cognitive behavioural therapy and its relevance to nursing. British Journal of Nursing, 20(22), 1443-1447. doi: 10.12968/bjon.2011.20.22.1443.

30) Marquès-Brocksopp L (2014) Mindfulness, spiritual well-being, and visual impairment: An exploratory study, British Journal of Visual Impairment. 32(2), 108-123. doi: 10.1177/0264619614528343.

31) Suzukamo Y, Kumano H \& Iwaya T (2001) Development and validation of "The Nottingham Adjustment Scale Japanese Version" which measures psychological adjustment to the visual impairment. The Japanese Journal of Rehabilitation Medicine, 41, 609-618. doi: 10.15064/jjpm.41.8_609.

32) Wolffsohn JS \& Cochrane AL (2000) Design of the low vision quality-of-life questionnaire (LVQOL) and measuring the outcome of low-vision rehabilitation. The American Journal of Ophthalmology, 130(6),793-802. doi: 10.1016/s00029394(00)00610-3.

33) Musa R, Fadzil MA \& Zain Z (2007) Translation, validation and psychometric properties of Bahasa Malaysia version of the Depression Anxiety and Stress Scales (DASS). ASEAN Journal of Psychiatry. 8(2), 82-89.

34) Omar R, Rahman MH, Knight VF, Mustaphal M \& Mohammed Z (2014) Mental health state and quality of life questionnaire in low vision assessment: a case report. BMC Res Notes, 7, 1-4. doi: 10.1186/1756-0500-7-667. 


\title{
ASIAN JOURNAL OF HUMAN SERVICES EDITORIAL BOARD
}

\author{
EDITOR-IN-CHIEF \\ Masahiro KOHZUKI Tohoku University (Japan) \\ EXECTIVE EDITORS \\ LEE, In Jae Hanshin Univerisity (Korea) \\ Satoru EBIHARA Toho University (Japan)
}

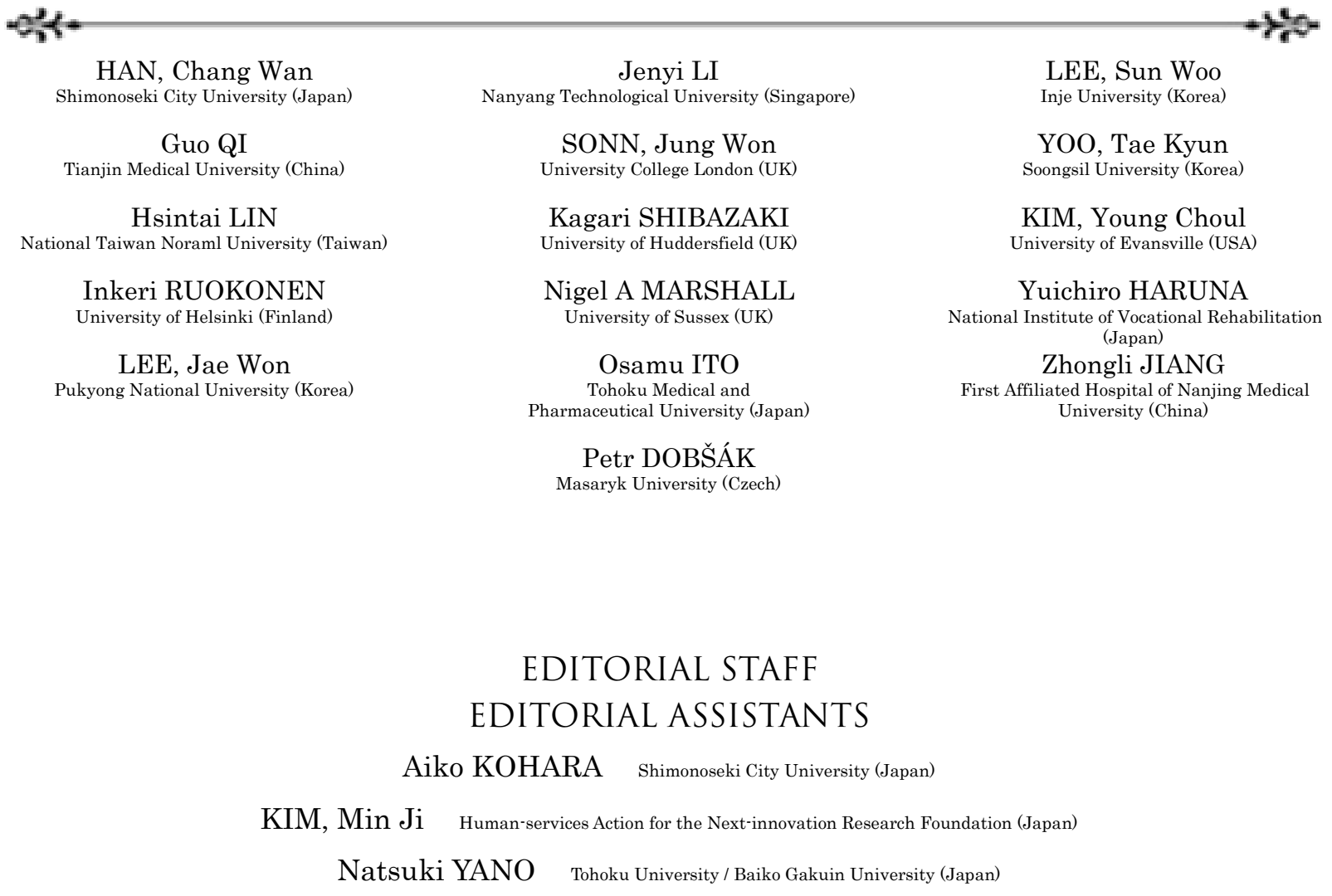

\section{ASIAN JOURNAL OF HUMAN SERVICES}

\section{VOL.18 April 2020}

(C) 2020 Asian Society of Human Services

$\begin{array}{ll}\text { Presidents } & \text { Masahiro KOHZUKI \& LEE, Sun Woo } \\ \text { Publisher | } & \text { Asian Society of Human Services } \\ & \text { \#1Floor Ohara Bill, 2-11-5, Takezaki-Town, Shimonoseki-City, Yamaguchi-Prefecture, 750-0025, Japan } \\ & \text { E-mail: ashs201091@gmail.com } \\ \text { Production } \mid & \text { Asian Society of Human Services Press } \\ & \text { \#1Floor Ohara Bill, 2-11-5, Takezaki-Town, Shimonoseki-City, Yamaguchi-Prefecture, 750-0025, Japan } \\ & \text { E-mail: ashs201091@gmail.com }\end{array}$




\section{ASIAN JOURNAL OF HUMAN SERVICES \\ VOL.18 April 2020}

\section{CONTENTS}

\section{ORIGINAL ARTICLES}

Structure of Care Managers' Approaches to and Awareness of "Nutritional Improvement" for Care-dependent Older People

Yuko FUJIO et al. p.1

A Multi-population Analysis of a Self-care Scale for Menstrual Pain:

Causal Relationships between Snacking and Menstrual Pain

Eriko YAMAMOTO p.18

Issues in Spousal Bereavement Support for Elderly Men in Japan

Makiko YAMAUCHI et al. p.33

A Fundamental Study on Health Anxiety in the Daily Life of Visually Impaired People Living in the Community and the Actual Situation of Patient Acceptance Systems at Medical Institutions

Keiko OMOTO p.48

Development of the Disability Awareness Program (DAP) scale:

Centering on the Content Validity Verification

Mamiko OTA et al. p.63

\section{SHORT PAPERS}

Medical and Care Collaboration between Nurse and Care-worker in a 'Kantaki' Setting: Time-Sampling Study

Yumi FUKUYAMA et al. p.74

Preliminary Study on Verb Acquisition Status and Related Factors in Children with Down Syndrome

Haruna OKAMIYA et al. p. 81

Experience of Reflecting Process in Graduate School for Clinical Psychologist

Norimasa ITAKURA et al. p.92

\section{CASE REPORTS / ACTIVITY REPORTS}

Analysis of Difficultiens faced by Home Health Nursing Practicum Instructors

Reiko HATAKEYAMA et al. p.100

UDL using ICT for Inclusive Learning; Learning Support for Students with

Diverse Learning Styles, Including Students who Need Special Support

Mitsuyo SHIMOJO et al. p.112

Published by

Asian Society of Human Services

Yamaguchi, Japan 